To appear in Encyclopedia of Early Modern Philosophy and the Sciences, general eds. Ch.

Wolfe and D. Jalobeanu (Springer, 2020)

\title{
Absolute and relative motion
}

\author{
Marius Stan
}

A debate in modern philosophy of physics is whether motion is absolute or relative. The debate began in the I6oos, so it deserves a close look here. Primarily, it was a controversy in metaphysics, but it had epistemic aspects too. I begin with the former, and then touch upon the latter at the end.

But first, some motivation. 'Absolute' and 'relative' were explanatory concepts in theories of motion, which were philosophical accounts of a privileged state synonymously called real, true, objective, or physical motion. The state was privileged because physical theory was about $i t$ : in early-modern science, descriptions and predictions were about the true motions of bodies. Caveat: 'absolute' and 'relative' were, and remain, deeply ambiguous terms; failure to clarify them well has caused much confusion and misguided controversy. It is doubtful that we can get a principled, univocal distinction (between absolute and relative) that applies both to current accounts and also to early-modern debates. ${ }^{\text {I }}$ Fortunately, it is possible to analyze these terms in ways that elucidate the I 7 th-century debates and make good sense of the relevant figures. But, to do so I must introduce a preliminary distinction.

Apparent vs true motion. Deeply entrenched and far reaching as the debate was then, it came on the steps of a very broad agreement: about its key presupposition. This wide agreement was a backdrop to the Copernican controversy and to the then-new mechanics. So, let us elucidate it first.

Look down at the earth, and consider the question: does it appear to move? Or does it seem at rest? Then look up at the sun and consider: does it seem to move across the sky, over a day? Or does it appear to be at rest?

\footnotetext{
${ }^{\mathrm{I}}$ See the arguments (that it is doubtful) in Rynasiewicz 2000.
} 
These questions are not hard, and no one disagreed about the answer then: trivially, the earth appears to rest, and the sun appears to move (around us), and so do all the stars. Now everyone also agreed on another point: these were just apparent motions or rest; but the sun, earth, and all else also have true states as well. They really move (or rest, as the case may be) no matter how they seem to behave relative to our senses. The Copernican controversy was really about the latter aspect. Specifically, both sides agreed that the earth appears to rest and the sun to move-it would be mad to deny it-but they disagreed about the true states of these bodies. Followers of Aristotle and Ptolemy argued that our earth truly rests (at the world's center) whereas the sun truly revolves around us, daily. Predictably, the Copernicans insisted that the sun is truly at rest, whereas the earth revolves around it, in an eccentric circle, over a year. ${ }^{2}$

The difference between true and apparent motion was critical to another, no less important area of early-modern science. It was a framing assumption for the new mechanics that began with Descartes. In I644, he had asserted and defended two laws of nature that jointly entail our modern principle of translational inertia, viz. that a body left to itself stays at rest or moves uniformly ahead. Though true, Descartes' law is not a statement about the apparent motions of bodies. In fact, these motions - the ones that appear to us perceivers on earth-fail the law of inertia trivially. ${ }^{3}$ Descartes knew it, and so he introduced a concept that does satisfy it: "philosophical motion," his term for motus in re vera, or as it really occurs in nature. ${ }^{4}$ This species of motion, he presumed, is privileged in that it obeys his three laws of nature, whereas "vulgar" motion, or as the common understand it, does not. While Descartes' posterity disagreed with him on nearly every other aspect, they all took his law of inertia for granted-and so implicitly they committed to the fact that it holds true of the bodies' true motions alone.

\footnotetext{
${ }^{2}$ There was also Tycho's hybrid picture, of course. The real, or true, Ptolemaic orbit of the Sun around the stationary earth is as presented in Ptolemy, Almagest, Book III. The earth's Copernican true motion is in De revolutionibus, Book I.

${ }^{3}$ Here are two examples known to the early moderns. Cannonballs shot along the local meridian deviate westward, and yet the horizontal component of their motion is inertial, so it should follow the meridian's north-south line. Objects dropped from rest deviate eastward, even though the only genuine force on them is downward, due to gravity. Of course, these violations of the Law are just apparent; they are due to the earth (to which the above motions are referred) not being a true inertial frame, because it spins.

${ }^{4} \mathrm{Cf}$. his Principles of Philosophy, Part II.
} 
In sum, both astronomy and mechanics then presupposed, and relied on, a distinction between true- and merely apparent motion.

\section{Metaphysics}

Though in broad agreement about the existence of true motion, the early moderns dissented sharply about its essence, or metaphysical constitution. Consider the question: what do true motion and rest consist in-what is their objective makeup? This was the genuine object of the 'absolute vs relative' debate: they were views about the nature of true motion. Specifically, two basic views, deeply at odds, emerged to answer the question of what true motion is. They were as follows. Absolutism: true motion consists in change of place in Absolute Space, at a rate set defined by Absolute Time. Relationism: true motion consists in kinematic change relative to some privileged matter frame, or reference setup. That setup is distinguished on metaphysical, dynamical, or merely pragmatic grounds.

In addition, there was also a radical fringe view. Relativism: there is no true motion and rest. Bodies always move or rest relative to other bodies; and none of these motions is metaphysically special or theoretically privileged. There is no fact of the matter about whether any object truly moves or rests.

The names above are modern, but we currently agree that, by and large, they are useful categories for early-modern historiography. ${ }^{5}$ Note that Relationism and Relativism are logical contraries, despite the similarity of their identifying labels. Now for some direct evidence from representative figures. Here is an acknowledgment that bodies have both apparent motions and also true ones:

if anyone dares say that the earth moves or the Sun rests, it is thrown back at him that he blasphemes, because Sacred Scripture asserts everywhere that the Earth rests and the Sun runs in the skies, like an athlete. To which they add another argument, viz. that this opinion cannot be true, because it is plain to everyone, based on their own eyesight, that it is not the Earth that moves but the Sun; and it is not the Sun that rests in the center of the world but the Earth. ...

However, we cannot conclude from that phrase that this is necessarily true. For in that phrase Scripture does not declare what is really the case [revera sit] but only what it appears to be [videatur] —as I shall demonstrate quite clearly in the Meditation

${ }^{5}$ Though very likely not good enough to capture post-Machian debates on space, time, and motion; again, see Rynasiewicz 2000. 
that follows. As to the second argument, I confess that it so appears to eyesight, namely that the Earth rests and the Sun moves in the sky. However, this is not so in reality [revera]. For, not everything that appears to the eye is true; nor is everything that is true conspicuous to the eye. (Lansberg I65I: i-iv, my italics)

Another one: "We judge rest to be both apparent as well as true" (Boulliau I639: IOI, my italics). And another one, from Kepler's earliest convert:

Copernicus makes the Sphere of the fixed stars be immobile, but states that the Zodiacal and the Equinoctial points move forward. Whence he concludes correctly that the places of the Fixed stars, which are in fact unmoved, only seem to the eye and imagination to fall back behind the Zodiac [revera immota, visu tantum ac phantasia in consequentia ferri]. Kepler assents to this opinion. Lansberg too was at one point of the right opinion in this matter-namely, that the fixed stars really are fixed [re immotas], as their name would have it. (Horrocks I678: 54, my italics)

Here is a pre-Newtonian statement of Absolutism: "local motion occurs either from one place in world space [spatium mundanum] to another; or in the relative space of some container. The former we call real and physical motion [realis, physicus], the latter relative motion [relativus]" (Borelli I667: I-2). And, a pithy statement of Relationism by Leibniz, in a pan-European bestseller: "I grant there is a difference between the absolute true motion of a body and a mere relative change of its situation with respect to another body. For when the immediate cause of the change is in the body, that body is truly in motion." Finally, a forceful assertion of Relativism, by Huygens, though unfortunately kept private until our times: "if we look carefully into the nature of motion, we shall find that this true motion and rest, as nearly all of them understand it, not only cannot be known, but does not exist at all in the universe."7

Grounding and structure. Absolutism got its name from a term for the sui generis entity that supports it, viz. Absolute Space. For Newton and his followers (on the ontology of true motion) space was absolute in several senses. I. metaphysically distinct from body. That is, space can subsist even if all matter

\footnotetext{
${ }^{6}$ Cf Ariew 2000: 49. Evidently, by “absolute true motion” Leibniz meant 'true motion' in his relationist sense, not Newton's. That is, he did not grant that true motion consists in motion in respect to Absolute Space (in fact, that is the view Leibniz combats in this passage). Rather, he thought that 'true' and 'absolute' are exact synonyms, hence they co-refer. I.e., for any single body, its Leibnizian absolute=true motion is one of the body's very many motions relative to all other bodies.

${ }^{7}$ See Huygens' Fragment VII in Mormino I 993; and cf. also Fragment X.A.
} 
perished; and has none of the essentials commonly ascribed to matter then. ${ }^{8}$ Further, space is immovable: it cannot be shifted, turned, nor set in motion; not even by divine agency. And, it is rigid: its parts, the absolute places, cannot be moved relative to each other, nor can they change shape or size. 2. causally inert. Space does not induce any kinematic or dynamical effects in bodies. ${ }^{9}$ Nor is it changed by bodies interacting and moving across it. 3. structurally immutable. The geometry of space, metric and affine, does not change over time; and neither does its topology. ${ }^{10}$ Moreover, these layers of structure are intrinsic to space itself; they are not parasitic on matter facts, nor are they induced by some mental agency, whether human or divine.

The same goes for time, which was absolute in the senses above (modulo its I-dimensionality), and also in another way. 4. simultaneous everywhere. For any two events, there is a fact about whether they occur at the same time or one is earlier, and the fact is not relative to particular observers, but to time itself. ${ }^{\text {II }}$ Newton supported most of these attributions of structure (to space and time) with arguments, some of which remained unanswerable; for an account of them in context, see Rynasiewicz I 995.

Finally, note the strategic place that absolute space and time occupied in early-modern ontologies. Their absoluteness supported the objective kinematic quantities required by the science of motion in classical regimes. More exactly: absolute space and time $\rightarrow$ correct theory of true motion $\rightarrow$ inertial mechanics and physical astronomy

\footnotetext{
${ }^{8}$ Bodies are extended too, but finite and bounded, whereas Absolute Space is infinite and unbounded. And, bodies are divisible in a strong sense: physical agencies can cause any body's parts to become separated by a finite distance. That is conceptually impossible with Absolute Space. Lastly, bodies affect our senses, causing perceptions, whereas Absolute Space is imperceptible. Newton made these points in De gravitatione, a youthful essay in metaphysics (cf. Newton 20I4).

${ }^{9}$ Some modern writers suggest that Absolute Space is responsible for undisturbed bodies continuing in their inertial motion, if they so move. Whatever the truth of this notion, it is anachronistic in our context, and it lacks evidential support from it. The early moderns did not think that force-free motion requires explanation (let alone by appeal to space itself); only deviations from inertial motion needed explaining (in terms of the powers of bodies, of course).

${ }^{\text {Io }}$ Topologically, Absolute Space was 3-dimensional, unbounded, continuous everywhere, dense, and connected. Though the term 'topology' arose in I 847, the key ideas behind it were already in place by $\mathrm{I} 700$.

${ }^{\text {II }}$ Confoundingly, Newton's opponents agreed with him about time being absolute in sense 4 above, though they had no good reason to assent to it.
} 
The arrow denotes metaphysical explanation. What gets explained ultimately is actual facts about spatial distances (to and from bodies) and their time-rates of change. However, the intermediate but sine qua non explanatory step is the concept of true motion. It is this concept that space- and time doctrines had to explain directly, by accounting for the "properties, causes, and effects" of true motion, as Newton put it memorably. It is not enough to articulate a sense in which space may be relative. ${ }^{\mathrm{I}}$

This fact is more momentous than it seems. To re-emphasize the point: any early modern doctrine of space and time must demonstrably entail a correct theory of true motion-or else it leaves mechanics without a good foundation: a grave defect of that space metaphysics, by any measure.

From this vantage point, we can see that most of Newton's opponents simply missed the point. Namely, it is beside the point to object to Absolute Space by gesturing at stories of how we might acquire the representation of space; or how the common allegedly use space talk (as Leibniz and Berkeley notoriously did to counter Newton). Even if true, their crude stories above remained beside the point, because the real task was to ground the inertialkinematic structure of the new science, not to dabble in armchair semantics. In regard to that task, however, Newton's opponents achieved far less than he did, philosophically. For a glimpse into why that's true, consider a deceptively simple question:

Relative to what material entity does a body free of impressed forces move uniformly in a straight line?

Strangely, Newton's opponents never confronted this question directly. ${ }^{\mathrm{I} 3}$ So, we have no clear picture of the early modern alternatives to Newton-Euler 'absolute' motion, let alone any idea if these alternatives were remotely good. Even less do we know the relationists' answers to another, cognate question:

Relative to what material entity does a force-free body move uniformly, i.e. it crosses equal distances in equal times?

This question is as hard as it is simple, and no one then answered it. ${ }^{14}$

\footnotetext{
${ }^{\text {I2 }}$ A recent, thorough account of early-modern doctrines of relative space is Slowik 2016.

${ }^{13}$ Huygens was a lone exception, but even he gave just a partial answer, which moreover remained private, unknown to anyone but him then; cf. Stan 2016.

${ }^{14}$ Except for Newton and Euler, of course, who answered it by rejecting its assumption, viz. that any material setup is adequate for that task. Euler pressed this very point on his opponents, in his $I 750, \S \S 3,6$.
} 
Put differently, we do not yet know what early modern advocates of relative motion thought in response to a dual question: What is an inertial frame, and what is an inertial clock? The metaphysical payoff of whether motion is absolute or relative ultimately pertains to this twin question, nothing else; and no early modern doctrine of space, time, and motion can be thought defensible unless it entails defensible answers to it. Once we grasp the force of this simple fact, we can see that, ultimately, relationists' attempts to bring in God-so as to counter Newton from sundry theological tenets-were futile and irrelevant. No refuge in divinity can absolve them of the task to ground the Law of Inertia - a fact not lost on Euler, who pressed them to tackle it head on:

[The Law of Inertia] is indubitably established, hence it must be grounded in the nature of bodies. And because it is Metaphysics' business to investigate the nature and properties of bodies, knowledge of this truth of mechanics may serve as a guide in the intricate researches of Metaphysics. For we would be right to reject all ideas and arguments in Metaphysics-however well-founded they may otherwise seemif they lead to conclusions contrary to the truths of mechanics; and one would be warranted in only admitting such metaphysical principles as can be reconciled with these truths. ... Thus it is always a great step in advance when one knows already, from other sources, some conclusions at which the first principles of Metaphysics ought to arrive eventually. And it is by these conclusions that the first ideas of Metaphysics must be regulated and determined. (Euler I750: § 2)

No one took him up on his challenge. So, we must conclude that, in the early modernity, the balance of argument favored absolutism about true motion. If that sounds inconclusive, here is another topic where absolutism prevailed.

Rotation. I begin with some relevant background facts. First, Huygens' I 673 work on centrifugal force, adapted to Newton's dynamics, entailed that a body in circular motion has a linear speed $w^{2} r$ directed along the local tangent to the orbit. Second, in the Copernican controversy the ultimately winning side had it that the earth truly rotates around its polar axis. Third, the evidence for ascriptions of true spin to a body did not involve reference to matter frames external to the spinning body. That is, the kinematic content of the evidence involved just acceleration effects (on test objects) relative to the rotating body itself, not any outside frames. ${ }^{15}$

\footnotetext{
${ }^{15}$ Huygens had taught how to attach test objects to a spinning system and infer the latter's angular speed $w$ from the tension-force between it and the test object. Newton had taught Hooke how to find evidence that the earth really spins: by dropping test objects from a height, and measuring their eastward deflection relative to the earth, not to any external frames such as the stars or the sun. For explanation, cf. Stan 2015 and 2016.
} 
These facts required explanation in terms of the two positions above. ${ }^{16}$ Really, an explanation would need to satisfy three conditions. i) to answer: if a body really spins, with respect to what does it move truly? ii) to show: that one's answer to the previous recovers the unique quantity and direction of instantaneous spin, as established by Huygens and Newton. iii) to explain: why does the standard evidence (for true spin) make no reference to any matter frames external to the system, if true motion consists in a special relation to that sort of frame?

Absolutism had an easy way meeting these conditions; it entails cogent answers, as follows. True spin consists in circular motion with respect to Absolute Space and Time. If a body so moves, its linear speed is $w^{2} r$, up to a translation. ${ }^{17}$ Finally, no evidence from changes relative to material frames is required, because true spin depend on no relations to such frames.

Relationism, however, tended to founded on the rocky shores of rotation. ${ }^{18}$ Most of Newton's opponents left us no clear picture of how their relationism accounts for true spin. Huygens alone had grappled with the challenge of rotation seriously, and the best he could do was to solve tasks (i) and (ii) above; the latter he had to answer twice to arrive at a cogent response. But (iii) seems to have eluded him entirely, even though a good part of his motivation for relationism was empiricism about our representation of corporeal motions. ${ }^{\text {I9 }}$ It is disappointing to see him miss the anti-relationist force of the evidence (for true spin) that he first taught us to marshal.

And so, if we set aside all irrelevant distractions, and examine the issue unfazed, it is not hard to agree that at least until the I 750 os defenders of the view that motion is absolute had a much stronger case than their relationist opponents. Thus we may reaffirm Earman's old verdict that no one should be afraid of Absolute Space.

\footnotetext{
${ }^{16}$ Here, relativism seems a non-starter, as it denies that rotation had any privileged quantities.

${ }^{17}$ Here, $r$ denotes a linear distance in Absolute Space: from the spinning body's absolute place (at an instant) to the absolute place of the center of rotation. And, $w$ denotes the rate of change with respect to Absolute Time: of the body's angular position in Absolute Space.

${ }^{18}$ It is a great merit of Earman 1989 to have identified rotation as a special acid test for assessing the strength of absolutism and relationism.

${ }^{19} \mathrm{Cf}$. the details in Stan 2016.
} 


\section{Epistemology}

The debates over absolute and relative motion had some epistemic aspects too, and they were no less thorny.

Start with absolutism. A corollary of the Newton-Euler theory of true motion is that single bodies have determinate velocities in respect to Absolute Space. But they are unknowable: no evidence can settle how fast they are. ${ }^{20}$

Here is why. In mechanics, any observation or experiment must be referred to a frame. Specifically, initial conditions must be described as distances (of mass- and force distributions) relative to that frame; then observed or predicted motions must be stated in terms of time-rates of change in these distances, viz. as speeds and accelerations relative to the frame. Mechanical experiments amount to using the laws of mechanics-in essence, Newton's laws of motion-to predict, from initial conditions, the future behavior of the system at issue, in terms of trajectories, speeds, and accelerations relative to the frame.

In two respects, however, the laws themselves are powerless. I. They cannot be used to discern whether the frame itself is truly in uniform translation or truly at rest. 2. They do not distinguish-hence, they do not single out as theoretically privileged-any one individual frame from an immensely large class of frames that are just as good as it. That is because in classical mechanics the only adequacy condition on a frame is that, relative to it, for any force $\mathrm{F}$ on a mass $A$, there exists a force $\mathrm{G}$ that the mass $A$ exerts on the source $B$ of $\mathrm{F}$, such that $\mathrm{F}$ and $\mathrm{G}$ are equal and opposite. As long as this condition obtains, any frame will do. ${ }^{2 I}$ This impotence in regard to the frames' true states is known as 'Galilean relativity.' So, the worry was that Newton's overall doctrine has an epistemic weakness: his philosophical theory of motion entails that 'true velocity' is a legitimate concept, but his empirical mechanics counts true velocities as unknowable parameters, because of Galilean relativity. This weakness was the target of some famous rebukes, such as Leibniz's complaint that Clarke thinks the "reality of motion does not depend on being observed.... I answer that motion does not indeed depend on being observed, but it does

\footnotetext{
${ }^{20}$ At least, not any evidence coming from mechanics. In late-classical physics, Michelson and Morley tried exploiting evidence from optics to settle such questions.

${ }^{2 I}$ I leave out as too difficult to address here the question of what a frame is in the first place, irrespective of its inertial credentials. In particular, neither the early moderns nor their latterday exegetes have examined what counts as a physical realization of the purely kinematic notions, 'coordinate system,' 'standard of length,' and 'chronometer.'
} 
depend on being able to be observed."22 Leibniz implied that the weakness above was a crippling defect of Absolutism. However, it would be too rash to concede him a point of such strength. Consider two rejoinders.

First, Newton did have an empirical criterion for fixing absolute velocities, backed by a principled choice of gauge (put anachronistically). When he reissued Principia he added a "Hypothesis I: The center of the system of the world is at rest." ${ }^{23}$ As warrant he cited the consensus omnium, or the confidence that none of his peers would disagree with him about it. ${ }^{24}$ Call that center W. The epistemic import of Newton's hypothesis is that it obviates his problem, as follows. i) bodies' velocities relative to $\mathrm{W}$ are always equal to their velocities in Absolute Space. ii) velocities relative to $\mathrm{W}$ are knowable-from the forces on the bodies, by means of Newton's techniques and results in his treatise. iii) ergo, velocities in Absolute Space are knowable after all, at least in principle.

Now for a more potent rejoinder. Newton's theory of mechanics allowed us for the first time to answer some central questions that had plagued Western science since Hellenistic times. The most important questions were these. I. What are the true orbits of the primary planets? 2. Which system of the world is true, the Copernican or the Tychonic? 3. How long does any regular process last, at celestial scales?

The Principia yields accurate answers, revisable to even greater accuracy, to these questions. Briefly, his answers were as follows. Ib. The seven primary planets move in conics. Specifically, their orbits are confocal ellipses, up to perturbations and a common velocity factor. 2b. Neither system is true. In reality, all planets revolve around the center of gravity of the solar system, and so does the sun. $3 \mathrm{~b}$. The duration of astronomical events is as inferred from the sun's apparent motion (relative to terrestrial observers) corrected by the Equation of Time. That is because the Equation is true, which the Principia entails and vindicates.

Now what do these empirical claims have to do with the epistemology of absolute and relative motion? There is a strong link between them, but it is

\footnotetext{
${ }^{22}$ In his Fifth Letter, paragraph 52 in response to Section 13 of Clarke's previous instalment (Ariew 2000: 49, my italics).

${ }^{23} \mathrm{He}$ inserted this item in Book III of the second edition (Newton I7I3: 373).

${ }^{24}$ Newton rated it a hypothesis not because he had no evidence for it, but because his official warrant fell short of what he required for knowledge claims to count as "deduced from phenomena," hence as beyond hypothetical according to his epistemic standards.
} 
hidden from view. In a nutshell (and separated for greater clarity) the epistemological import of Newton's three answers above is as follows.

i. evidence for his claims is gathered by 'deduction from phenomena.'

ii. such 'deductions' are underwritten by Newton's three laws of motion.

iii. but the laws presuppose motion in absolute space and time.

Before I proceed, a few words of explanation. To (i): Newton coined the phrase 'deduction from phenomena' to denote his logic of evidence, so as to distinguish it from the hypothetico-deductivist confirmation theories of Descartes, Huygens, and Leibniz. To (ii): Newton's laws underwrite deduction from phenomena in two senses. First, the laws serve as rules of inference, in addition to the standard rules of deduction. Second, the laws are constraints on inference: no orbits are allowed as predictive conclusions unless they are compatible with the laws of motion. ${ }^{25}$ To (iii): the key to understanding this idea is Newton's 'argument from causes,' stated mid-way in his Scholium to the Laws of Motion. It goes as follows. Impressed forces are both necessary and sufficient for changes in the true motion of any object. Now if we explain true motion as motion in absolute space, the condition carries over: any impressed force applied to a body changes its state of motion in absolute space; and only impressed forces can change that state, nothing else. However, the condition does not carry over to relative motion. That is, to change a body's relative motions - any of them, really, including the one that might count as its true motion-impressed forces are neither necessary nor sufficient. Ergo, forces (or at least the impressed forces that support Newton's inertial mechanics) do not correlate with the relative motions of bodies; whereas they always correlate, as accurately as we please, with their motion in absolute space. $^{26}$

The lesson of this evidential argument, I submit, is that Newton and Euler bested their opponents (on the issue of true motion) in epistemology too, not just in metaphysics. Briefly put, they earned a right to say that evidence gathered in gravitational mechanics and astronomy is, at the very least, compatible with their theory of true motion (defined as change of absolute place). So, for a relationist to carry the day, she would have needed to give not just a provably better metaphysics of true motion qua relative to matter, but

\footnotetext{
${ }^{25}$ More exactly: only orbits obtained by integrating the Second Law twice in respect to time.

${ }^{26}$ I explained Euler's version of the 'argument from causes,' and its relation to Newton's inference, in Stan 2012.
} 
also a better epistemology. Namely, one that connects her preferred concept (of true motion) to laws of force and to relative accelerations-relative in her official sense, not just any sense-and then to observational evidence compatible with these laws and also within the standards of accuracy that Newton had achieved with his theory.

Needless to say, no such epistemology of relative motion was on offer then-at least not until the later Kant attempted one in the I780s, past the historical threshold of this volume. Hence we must conclude that, at least until the I750s, the view that true motion is absolute motion had the philosophical upper hand over its competitors. And so, the epistemic situation of relationism closely mirrors its weaker state in metaphysics. Just as in metaphysics all that they really had was polemic posturing and deflective manoeuvers but no constructive accounts; in epistemology they spent all energy hammering home the point that Newton's absolute velocities are unknowable. But that is far from enough to triumph over absolutism.

In fairness, the epistemology of true motion has been much less explored, and so is much less well understood, than the metaphysics of it. So far, we merely have an account of Newton's deduction from phenomena. ${ }^{27}$ But, we are far from having a good grasp of how, e.g., Leibniz cashed out theorymediated knowledge of fundamental parameters (like, true accelerations, time lengths, and the exact value of $\mathbf{g}$, the acceleration of gravity above ground). Even less do we know why he thought that aesthetic criteria (like, simplicity) are conducive to knowledge of fundamentals in dynamics.

\section{Bibliography}

Ariew, R. 2000 (ed.). Leibniz and Clarke: Correspondence. Hackett.

Borelli, G.A. I667. De vi percussionis. Bologna.

Boulliau, I. I645. Astronomia Philolaica. Paris.

Earman, J. I989. World enough and space-time. MIT Press.

Euler, L. I750. Réfléxions sur l'espace et le tems. Histoire de l'Académie Royale des Sciences et Belles Lettres (I748), 324-33. Berlin.

\footnotetext{
${ }^{27}$ The strongest statement of evidence in Newton's gravitation theory is Smith 2014.
} 
Horrocks, J. I673. Astronomia Kepleriana, defensa et promota. Opera Posthuma, I-239. London.

Lansberg, Ph. I65I. Commentationes in motum terrae. Middelburg.

Mormino, G. I993. Penetralia Motus: la fondazione relativistica della meccanica in Christiaan Huygens, con l'edizione del Codex Hugeniorum 7A. Firenze: La Nuova Italia.

Newton, I. 20I4. De gravitatione. Philosophical Writings, ed. A. Janiak, revised edition, 2958. Cambridge University Press.

Rynasiewicz, R. I 995. 'By Their Properties, Causes and Effects': Newton's scholium on time, space, place and motion. Studies in History and Philosophy of Science 26: 133-I 53.

Rynasiewicz, R. 2000. On the distinction between absolute and relative motion. Philosophy of Science 67: 70-93.

Smith. G.E. 20I4. Closing the loop: testing Newtonian gravity, then and now. In Z. Biener and E. Schliesser (eds.), Newton and Empiricism, 262-35I. Oxford University Press.

Slowik, E. 20I6. The deep metaphysics of space. Springer.

Stan, M. 20I2. Newton and Wolff. Southern Journal of Philosophy, 50: 459-8I.

Stan, M. 20I5. Absolute space and the riddle of rotation. Oxford Studies in Early Modern Philosophy, 7: 257-308.

Stan, M. 20I6. Huygens on inertial structure and relativity. Philosophy of Science 83: 277-98. 